\title{
Da dogmática jurídica
}

\section{Paulo Carneiro Maia}

\begin{abstract}
SUMÁRIO - 1. - Proêmio. 2. - Importância da proposição. 3. - Trajetória do pensamento filosófico jurádico de Pedro Lessa. 4. - Sua definição do direito. 5. - Concepção no criticismo. 6. - Concepção no krausismo. 7. - Concepção de Thering. 8. - Influências sofridaś por Pedro Lessa na conceituação do Direito. 9. - Valor atribuível à dogmática jurídica. 10 - Apreciação sobre a inconciliabilidade de àrte jurídica. 11. - Identificação do verdadeiro papel da dogmática jurídica. - 12 . Conclusão.
\end{abstract}

1. A concepção doutrinária de Pedro Lessa sôbre a dogmática jurídica constitui um ponto cardial para meditações desapaixonadas. (1).

Mestre de gigantesca envergadura moral e de fascinante intelectualidade que lhe asseguraram singular destaque na Faculdade de Direito de São Paulo, para a qual ingressou em 1888 pelo portal de dois concursos que o notabilizaram (2), projetando-se em outros setores, não se

(1) Trabalho feito para a cadeira de Filosofia do Direito, do $2^{\circ}$ ano do Curso de Doutorado, entregue ao Prof. Miguel Reale, em 1953.

(2) Em 1887, depois de ter iniciado sua vida pública como Secretario da Relação de S. Paulo, inscreveu-se Pedro Augusto CarNeIRo Lessa em concurso na Faculdade de Direito dêsse Estado. Apesar de ter obtido o primeiro lugar, foi preterido por Frederico ABranches, prócer politico apoiado pelo partido então dominante. 
acorrentou Pedro Lessa à ortodoxia positivista em que se moldara. Quando subiu à cátedra, já o disse o eminentissimo Prof. Reynaldo Porchat, tinha o espírito "enriquecido pelo ensinamento que granjeara no convívio com os melhores autores. Entrou de passo firme por êste templo da metafísica, vibrando golpes sôbre golpes. O seu método foi o positivo, que êle chamava científico, com a intenção de precisar-lhe o significado. E erudito, talentoso, pugnaz, dialético, mordaz e verboso, sacudiu as construções frágeis tecidas sôbre o velho apriorismo, e, manejando o método indutivo com os processos científicos da observação, experimentação, comparação e generalização, tornou-se invencível no ataque." (3).

Traçando o perfil da inconfundível personalidade de Pedro Lessa, anos depois, o Prof. Miguel Reale, em discurso de posse da mesma cátedra que tem sabido manter alta, merecendo ser considerado um dos provocadores do renascimento da Filosofia no Brasil, não dissimulou se afastar de sua "orientação filosófico-jurídica", reconhecendo-lhe deficiências. Proclamou-o como sentiu: "Não me coloco, pois, entre aquêles que se dão à desagradável tarefa de destruir a obra de Pedro Lessa, atribuindo-lhe tão sòmente méritos técnicos de jurista, porque o que nos cabe é apreciar com objetividade a sua posição na história do pensamento filosófico-jurídico do Brasil em geral, e desta Faculdade em particular.

\footnotetext{
Aberto outro concurso, em 188.8, nele se increveu, obtendo a melhor classificação sendo, então, nomeado lente substituto aos 16 de maio daquele ano. Três anos decorridos, era nomeado professor catedrático por decreto de 21 de março de 1891, lecionando durante 20 anos, já que, em 1907, foi guindado ao Supremo Tribunal Federal, na vaga deixada pelo Ministro Lucio de Mendolsça.

(3) Oração proferida por ocasião do centenário dos cursos juridicos no Brasil, em 11 de agôsto de 1927, sob o título "O Pensamento Filosófico no Primeiro Século da Academia." - (Revista da Faculdade de Direito de São Paulo, São Paulo, Tipografia Siqueira, vol. 24, págs. $367 / 368$ ).
} 
Não isenta de falhas e defeitos, a sua obra há de ficar pelo que representou no sentido de uma compreensão mais exata dos fenômenos jurídicos, cujo real valor e significado só se compreendem no sistema orgânico das fôrças sociais." (4)

Anima-nos a mesma idéia construtiva, guiados por igual liberdade que era, de resto, apanágio daquele juristafilósofo, na investigação de seu enunciado. Distanciados estamos de qualquer propósito de crítica demolidora. Há de ser visto, pois, o nosso intento na sua pars construens e não naquilo que possa ser vislumbrado como sua pars destruens. Mesmo porque não há que destruir em quem soube construir com amalgama da sabedoria.

Rumando por êste caminho, visamos a perquirir, numa tentativa de investigação bem intencionada, o que há de vivo ou de morto na conceituação que Pedro Lessa tem da dogmática jurídica. Acenamos, bem por isto, de início, sua trajetória espiritual, de vez que esta não seria a sede adequada à sua biografia (5), apenas para demarcação de princípios, embora imprecisos como os distantes espigões das serranias.

(4) Discurso feito perante a Congregação da Faculdade de Direito da Universidade de São Paulo ao tomar posse da cátedra de Filosofia do Direito, em 14 de maio de 1941. (Dois Discursos, 1942, S. Paulo, Emp. Gráfica da Rev. dos Tribunais Ltda., pág. 9).

(5) Dados apreciáveis foram fixados por Clóvis Bevilaqua no discurso pronunciado, em sua memória, em sessão pública de 27 de outubro de 1921, na Acad. Bras. de Letras, (Rev. da Acad. Bras. de Letras, Rio de Janeiro, Ed. do Anuário do Brasil, ano XIX, vol. 27, no 77, págs. 100/106). O “Adeus" deu-lhe Coelho Neto propondo a todos o juramento - "amar e honrar o que êle tanto amou, honrou e engrandeceu: a Pátria." (ibidem, págs. 110/112. Fî̀z-lhe a crônica Humberto de Campros. (Carvalhos e Roseiras, Rio de Janeiro, 1941, W. M. Jackson Inc., págs. 139/145). Valioso manancial se contém em dois apreciáveis repertórios (Revista da Faculdade de Direito de São Paulo, S. Paulo, Tipografia Siqueira, vol. 22, pág. 262; Revista do Supremo Tribunal Federal, Rio de Janeiro, vol. 30 , págs. $3 / 64$ ). 
2. A proposição não ẻ meramente acadêmica como pode parecer. Nem se reveste de simplicidade. Envolve a questâo substancial do valor da dogmática, como ciência ou como arte, e seu enquadramento. Exprimindo as divergências entre os escritores, escreveu o Prof. Miguel Reale em magnífica síntese que merece ser relembrada: "Uns, e são os que atendem mais à expressão formal do Direito, identificaram a Dogmática e Ciência do Direito, declarando que a Ciência que tem por objeto a formação ou elaboração das leis não é a ciência juridica pròpriamente dita, mas a Política ou a Teoria Geral do Estado. O trabalho do jurista não compreenderia, dessarte, a indagação das causas e dos motivos das normas, a não ser como elemento auxiliar de exegese na aplicação das leis aos casos concretos.

Outros, ao contrário, procurando achegar a Ciência do Direito às chamadas Ciências naturais, distinguem a Ciência do Direito da Dogmática, considerando a primeira uma ciência verdadeira, e a segunda uma arte ou a explanaçáo de uma arte." (6).

Se a assinalação de dissentimentos entre autores não é confortador, muito menos se-lo-á reflexionar com a própria autoridade contraditada. Atitude menos cortês. caracterizando o argumento denominado ad hominem (7), mas que nos vemos constrangidos a assumir porque será

(6) Teoria do Direito e do Estado, 1940, S. Paulo, Livraria Martins, no 6 , pág. 11 .

(7) Focalizando o enunciado, adverte, com oportunidade, CARuos Maximiliano: "Não é delicado e produz mau efeito o invocar a autoridade daquele perante o qual ou contra quem se pleiteia ou discute; especula-se, dêste modo, com a vaidade, que interdiz o abandono e a retratação do êrro. Chama-se argumento ad hominem, ad judicem ou ad curiam, conforme se refere a anterior parecer do contraditor, de um juiz, ou de tribunal coletivo. Tal processo fere ao mesmo tempo as conveniências e a lógica." (Hermenêutica e Aplicação do Direito, 1941, S. Paulo, Livraria Editôra Freitas Bastos, no 339 , págs. 329/330). 
de través do desdobrar do pensamento de Pedro Lessa qué iremos situar o problema.

3. Em 1896 sustentou Pedro Lessa, em preleção dada à publicidade, que a dogmática jurídica era uma ciência. Partindo do conceito de arte a de ciência para assinalar que "tôda ciência tem exclusivimente por objeto conhecer" as leis, as relações necessárias entre os fenômenos", mostrou como o jurisconsulto, quardo aplica o direito, desenvolve sua atividade no domínio artístico, porém que "êsse trabalho artístico carece ser precedido do estudo de verdades científicas de que a arte è mera aplicação." Essas verdades científicas não estão, sòmente, nos princípios fundamentais, "mas também nas leis particulares, nos . $\mathrm{co}_{-}$ rolários, nas deduções ou desenvolvimentos dêsses princípios, que formam o conteúdo da dogmática jurídica." (8):

Tempos decorridos, ou melhor, em 1912, o mesmo laureado professor, quando já tinha deixado a cátedra, passou a defender idéia diametralmente oposta. Com a publicação de seu precioso livro, pôs em realce que "sòmente pelo caráter empírico, por tantos séculos imprimido ao estudo do direito, e pelos arraigados preconceitos que ainda hoje dominam tantos cultores dessa doutrina, incapazes, pela falta de preparo científico, de formar um conceito exato acerca da natureza da ciência, tornou-se possívèl, então, explicar-se "o absurdo da inclusão da dogmática jurídica entre as ciências, ou da sua qualificação como ramo da ciência do direito." E depois de acenar que ela "tem por objeto o dogma do direito, isto é, os cânones, as regras do direito positivo, as leis (no sentido técnico, especial, do têrmo), escritas ou consuetudinárias", finaliza de modo incisivo: "A dogmática jurídica encerra um conjunto de preceitos, formulados para a realização de fins determi-

(8) Metodologia Jurídica, in Revista da Faculdade de Direito de São Paulo, S. Paulo, Espinola, Siqueira \& Cia., vol. 4, págs. 26/27. 
nados: é a explanação de uma arte. Confundi-la com a ciéncia importa desconhecer um dos mais vulgares elementos de lógica." (9).

Albergando esta idéia como a definitiva, por circunstância cronológica, a traduzir o prevalecente pensamento. filosófico-jurídico, teremos de perquirir dos fatôres que a motivaram ou a influenciaram.

4. A especulação nos conduz numa retilínea à definição do Direito, para logo deparada, que Pedro Lessa dá como sendo "o conjunto orgânico das condições de vida e desenvolvimento do individuo e da sociedade, dependentes. da vontade humana e que é necessário sejam garantidas pela fôrça coercitiva do Estado." (10).

Diretriz resultante da glosa generalizada sôbre as três: formas essenciais da ciência do direito - a dogmática, a histórica e a filosófica - precisando o acolhimento de ciência una e admitindo o pressuposto do monismo.

Com êste enunciado estariamos em condições de apreciar a definição legada por PEdro Lessa, verificando, assim, a qualificação da dogmática jurídica.

Todavia, representando as definições, de ordinário, uma atitude mental ou filosófica a reclamar uma penetração subjetiva (11), corre-nos o dever de apurar as razões ou fatôres desta construção jurídica, antes de qualquercrítica.

(9) Estudos de Filosofia do Direito, Rio de Janeiro, 1912, Tipografia do Jornal do Comércio, Rodrigues \& Cia., págs. 45/46 e 52 .

(10) Op. cit., pág. 62 .

(11) Lembra Martinez PAZ, de cuja lição nos recordamos nesta altura, que, "como una definición no es ordinariamente nada más que el análisis del contenido de un concepto, no puede ser estudiada en si misma sino en relación a la actitud que traduce frente a los problemas de la filosofia." (Sistema de Filosofia del Derecho, Buenos Aires, 1940, Libreria y Editorial El Ateneo, pås. 48) 
Verificaremos, pela observação dos fatos e das idéias. que a definição de direito de Pedro Lessa é uma acomodação dos enunciados de Kant, Krause e Ihering. Bastará: atentar para a conceituação de cada qual deles.

5. O filósofo de Koenigsberg, um dos precursores da concepção organicista da sociedade (12), dissertando sôbre o princípio universal do direito, define: "Est juste toute action qui n'est point, ou dont la maxime n'est point un. obstacle à l'accord de la liberté de l'arbitre de tous avec la liberté de chacun suivant des lois universelles." (13).

Desta definição vulgarizada (14) emerge nitida a idéia de liberdade, de arbitrio, já que para KANT o princípio

(12) Antes de KANT o direito era definido dos mais variados. modos; êle lançou a idéia de condicionalidade. Foi um dos precursores da teoria orgânica participando do movimento reacionário. No fim do século XVIII e comêço do XIX, registra SorokrN, houve uma reação “de la pensée sociale contre les conceptions atomistes, individualistes et mecanistes de la période précédente. Cette reaction prit la forme d'une renaissance de diverses interprétations organiques. Les théories contractuelles de la société, les théories de sa nature artificielle, et les théories de l'atomisme sociologique perdirent tout crédit. Leur place fut occupée par les théories de Bonald, J. de Maistre, E. Burke, Adam Müller, Herder, Lessing, Fichte, E. Kant, Schelling, H. Léo, Hegel et d'autres dans lesquelles divers caractères de la conception organique étaient établis.” (Les Théories Sociologiques Contemporaines, Paris, 1930, Payot, trad. de René Verrier, pág. 154)

(13) Principes Métaphysiques Du Droit, Paris, 1853, Librairie Philosophique de Ladrange, trad. de Joseph Tissot, § C, pág. 42.

(14) O texto original, pouco acessível, soa da maneira seguinte: "Das Recht ist also der Inbegriff der Bedingungen, unter denen die Willkuer des einen mit der Willkuer des andern nach einen allgemeinen Gesetze der Freiheit zusammen vereinigt werden kann." (Recht und Sitte-Die Kulturphilosophie - in "Die Drei Kritiken", selecionado e editado por Raymund Schmidt, Alfred Kroener Verlag, Leipzig, s/d, pág. 362). Encontradiça é a tradução: o direito é o conjunto das condições segundo as quais o arbítrio de cada um pode coexistir com o arbítrio dos demais, de har- 
indispensável ao conhecimento humano são as formas, moldes, ou categorias preexistentes à elaboração dos nossos juizos.

O clássico Del Vecckio, mergulhando no âmago do kantismo, extraiu, precisamente, esta conclusão. Externoua com tal limpidez e concisão que, por proporcionar 0 enunciado que almejaríamos, não nos furtamos de transcrevê-la fugindo às deformações de uma síntese ou tradução: "In questa definízione (o massima della coesistenza) si riafferma il concetto della libertà come supreme valore etico. L'uomo deve essere rispetato nella sua libertà, cioè non deve essere considerato o trattato come cosa, come strumento o mezzo, ma come fine in se stesso (Selbstzweck). La libertà é un diritto naturale, innato (la distintione tra diritti naturali ed acquisiti, fatta dai precedenti scrittori di diritto naturale, fu accettata dal Kant); anzi, tutti i diritti naturali si compendiano, secondo il Kant, in questro diritto di libertà. In vero, la libertà ed il valore supremo che colloca l'uomo sopra il mondo dei fenomeni. Se l'uomo

monia com uma lei universal de liberdade". Ao fazê-la os tradutores, atendendo ao mais exato sentido do vocábulo "willkuer", preferem traduzi-lo por "arbítrio" a por "vontade". De resto, conjuga-se melhor com o pensamento sistematizado do autor e com o sentido etimológico da palavra, como, semelhantemente, à arbitrariedade o ventilou Ihering (El fin en el Derecho, Buenos Aires, 1946, Editorial Atalaya, no 162, pag. 176). Estranhável, bem por isso, que Orris Soares, em seu dicionário, ora dado a pulblicidade, com a apresentação de "obra monumental", haja incidido na condenação de usar a palavra "vontade" em lugar de "arbítrio", no transmitir a definição do Direito como "conjunto das condições em que a vontade individual de cada um pode unir-se, associar-se à vontade individual de outrem, em harmonia com a lei universal da liberdade." (Dicionário de Filosofia, Rio de Janeiro, 1952, Departamento de Imprensa Nacional, vol. I, pág. 346, voc. Direito) Será, talvez, um daqueles "descuidos tão graves" ou a "falta de convivência direta" com os textos, na crítica do Prof. Mrauel Reale, pondo a perder a invocação do dicionarista. (Revista Brasileira de Filosofia, S. Paulo, 1952, Emprêsa Gráfica da Revista dos Tribunais Ltda,, vol. 2, fasc. IV, págs. 762/767) 
fosse solo un fenomeno, sarebbe determinato, come tutto ciò che appartiene alla natura. Ora, esso appartiene bensi alla natura in quanto ha un aspetto inferiore; e perciò è determinato, e si può dimostrare che ogni azione, come fenomeno, discende necessariamente da certe cause (in questo senso il Kant é, con ragione, determinista). Ma, d'altrapartē, l'uomo ha in sè un mondo di determinarsi superiore a quello della causalità naturale; la deliberazıne, in quanto procede dall'essere autonomo del soggetto, han un significato che va oltre il mondo dei fenomeni. L'uomo é libero in quanto si determina secondo la legge morale, che è un principio assoluto, implicito nel suo stesso essere. Prodotta che sia l'azione, essa apartiene all'ordine dei fenomeni, e come tale appare determinata. Cosi si conciliano la libertà e il determinismo.

Nella valutazione del diritto di libertà il Kant ha subito l'influsso del Rousseau, come si deduce dalla stesa sostanza del suo sistema filosofico, e anche da una sua esplicita confessione (egli scrisse: Vi fu un tempo in cui credetti che il maggior valore consistesse nell'intelligenza, e che lo scopo supremo della vita fosse la conoscenza. Il Rousseau mi ha fatto ricredere, e mi ha persuaso che vi é qualche cosa di superiore: la libertà e la moralità). Di qui la dottrina kantiana del primato della ragion pratica su quella teoretica." (15).

Discorrendo acêrca do idealismo transcendental ou criticismo, Pedro Lessa, a despeito de considerar falso o sistema de KANT, sublinha a característica de que, para o filósofo alemão, a liberdade é inseparável da razão e nela se concentram os direitos: "todos os direitos se reduzem a um só, que é a liberdade compatível com a de todos os outros homens segundo uma lei universal." (16).

(15) Lezioni di Filosofia del Diritto, Milão, 1950, Dott. A. Giuffre, pág. 86.

(16) Op. cit., págs. 294/295. O capitulo de seu livro em que se contém essa passagem, anteriormente, Ifôra resumido para os alu- 
É a lei universal de direito que, anotando afinal, Tissor traduz assim: "agis extérieurement de telle sorte que le libre usage de ton arbitre puisse se concilier avec la liberté de tous suivant une loi universelle"... (17).

Aqui, então, Pedro Lessa se encontra com Kant ou sofre sua influência, pois, ao definir o direito, deu-lhe a déia de condicionalidade, que reclama a de liberdade. A locução usada por êle, "conjunto orgânico das condições...", ou seja, complexo de formas condicionantes da experiência jurídica possível, corresponde, em substância, ao "livre arbítrio de cada um", a se harmonizar com o "livre arbítro de todos" que Kant coloca em primeiro plano no seu sistema metafísico. Ambos convergem para o mesmo ponto domiante que é o respeito aos limites da liberdade.

A definição de KANT poderá não ser isenta de crítica, notadamente porque almejou dar, não o sentido da palävra, mas a explicação da natureza do direito e sua origem metafísica, segundo a censura branda de LaLAnde. (18). Irrecusável, entretanto, apesar da reprovação de Pedro. Lessa (19), que ela se refletiu em sua própria definição de maneira marcante.

nos do $1^{0}$ ano de bacharelado publicado em 1902. (Revista da Faculdade de Direito de São Paulo, S. Paulo, 1902, Tip. Espinola, Siqueira \& Cia., vol. 10, págs. 217/242)

(17) Op, cit., pág. 43.

(18) Merece, aqui, ser destacada a observação do acatado Prof. na Sorbonne, ad unguem: "Nous avons éliminé, dans cet article et dans le précédent, toutes les definitions qui prétendent à donner, non le sens du mot, mais l'explication de la nature du droit, et son origine métaphysique, p. ex. la formule du Kant, definissant le droit par les conditions nécessaires à l'accord des volontés suivant une loi de liberté. A cette conception s'oppose la conception de la liberté comme résultant au contraire du rapport des droits. La liberté est le pouvoir qui s'appartient à l'homme de faire tout ce qui ne nuit pas au droit d'autrui." (Vocabulaire Téchnique et Critique de la Philosophie, Paris, 1938, Librairie Felix Alcan, vol. I, pág. 180, voc. Droit).

(19) Não titubeou o festejado catedrático em afirmar que “desde os seus primórdios o sistema de Kant é falso", ressentindo- 
6. Do racionalismo harmônico de Krause, o qual é um continuador de KANT, de um kantismo derivado ou de grau inferior, emerge o pensamento de dependência da vontade humana. A expressão "dependentes da vontade humana”, colheu-a Pedro Lessa em Krause.

Do transunto de José Mendes, com efeito, se apura a definição de Krause concebida nestes têrmos: "O conjunto das condições temporais dependentes da vontade humana e necessárias para a realização harmônica e plena do destino individual e social." (20).

Empregando a palavra "condições", comum aos bons conceitos, Krause aceitou a tese da condicionalidade de KANT com um adminículo; aditou à definição de direito a expressão "dependentes da vontade humana". Lê-se, a propósito, num de seus divulgadores, qual José Mendes, ponderação que se afina com êsse enunciado: "O primeiro filósofo que empregou na definição do direito, a adequada, precisa e significativa palavra condição foi KANT. Mas, quem concebeu a condição em seu sentido completo, como o têrmo característico para exprimir as relações orgânicas de determinação, de ação e de influência reciprocas, em que existe e desenvolve-se também tudo no mundo moral e social, foi Krause.

Éste princípio orgẩnico e regulador, destinado a manter a harmonia e a saúde do corpo social, foi reconhecido por Krause como o princípio completo do direito, determinado desde então como o conjunto orgânico das condições livres

se a sua definição do "mesmo formalismo" e da "mesma vacuidade" (op. cit., págs. 301 e 306). Seguiram-lhe a esteira, bordando iguais comentários, os Professôres José Mendes, o qual, ainda. apontou o defeito negativo daquela definição (Ensaios de Filosofia do Direito, S. Paulo, 1903, Duprat \& Cia., $§ 87$, págs. 301 e 316) e João Arruda (Filosofia do Direito, S. Paulo, 1942, Emp. Gráfica da Rev. dos Tribunais Ltda., vol. 1, págs. 96/97)

(20) Op. cit., § 91, pág. 398. 
para a realização harmônica do destino hưmano, afirma seu discípulo Ahrens." (21).

Expondo as idéias substanciais de Krause, destaca JoÃo Theodoro Xavier, em sua rara obra, os princípios jurídicos agasalhados por aquêle secretário de KANT. A relação de condicionalidade é circunstância ali posta em relêvo: "o direito diversamente é ciência especial que expõe o complexo de condições dependentes da vontade humana, necessárias ao cumprimento do fim assinado ao homem por sua natureza racional." E, depois de dar livre curso ao pensamento de Tiberghien, expositor belga do krausismo, acrescenta: "Circunscrito pois ao domínio da atividade livre repousa todo direito sobre a relação de condicionalidade entre os meios a a finalidade racional do homem." (22).

(21) Op. cit., § 91, pág. 399. Escreve, em verdade, AHrens, discipulo de Krause, que "le droit, comme principe d'ordre, est enfin un principe d'harmonie; car, en établissant une conformité de rapports entre toutes les personnes et toutes les choses, il harmonise aussi la vie sociale. C'est cette idée de l'harmonie que Platon, le premier, a comprise comme un caractère distinctif de la justice. La Justice, dit-il, est la vertu par laquelle les autres son liées, coordonness et harmonisées entre elles. Elle est la même, ajoute-t-il, dans l'individu et dans l'Etat. En effet, de même que l'homıme individuel mène une vie juste quand il cultive chaque force de l'âme en elle-même et en harmonie avec les autres, de même la justice de l'Etat consiste à soutenir toutes les forces, toutes les parties du corps social, et à les placer dans des rapports harmoniques. Cette conception de Platon est vraie et profonde, et il importe de la rappeler aujourd'hui que les esprits semblant oublier que la justice bien ordonnée commence par soi même, c'est-à-dire que chacun doit mettre d'abord l'ordre dans son âme et dans toutes ses forces actives, s'il veut qu'un ordre réel et durable s'établisse dans la societé." (Cours de Droit Naturel ou de Philosophie du Droit, Bruxelas, 1853, Meline, Cans et Cie., págs. 170/171)

(22) Teoria Transcendental do Direito, S. Paulo, 1876, Tipografia de Jorge Seckler, $\S 3 / 5$, pág. 325 . 
Viva é a expressão culminante de Krause, — dependência da vontade humana - na definição de Pedro Lessa. E se o krausismo exerceu tão profundo entusiasmo em vários pensadores do mundo, como observa Recasens Siches (23), não é de se estranhar que, embora hoje de diminuta influência, tivesse encontrado ressonância em um discípulo. de um seu discipulo. (24).

7. Ao receber essas duas doutrinas, imprimiu-lhes IHERING, poderoso pensador e respeitado jurisconsulto que pontificou na Alemanha no século XIX, um conteúdo nìtidamente sociológico. Estudando a missão do direito, cuja constante é o interêsse, trouxe para embasamento de sua. definição a noção de condições de vida. Definiu, então, depois de perquirir: "Cual es, pues, el fin del derecho? Hemos visto que el fin de los actos del ser animado reside en la realización de sus condiciones de existencia. Recogiendo esta definición, podemos decir que el derecho representa la forma de la garantia de las condiciones de vida.

(23) Relaciona o autor paises como a Espanha, Bolivia, Méxi-co e tantos outros em que o pensamento krausista teve representação relevante fazendo a reflexão paralela de que "el krausismo, como sistema filosofico, y singularmente su Teoria juridica, puede considerar-se en general como una posición que hoy ha sido ya superada." (Grorgio deL Vecchro, e Luis Recasens Siches, Filosofia del Derecho e Estudios de Filosofia del Derecho, México, 1946, Unión Tipografia Editorial Hispano-Americana, vol. II, págs. $332,342,423$ e 568 .)

(24) O venerado catedrático foi como João ARRUdA, seu sucessor, aluno de JoÃo Theodoro Xavier. Esse teve por mestre Krause, que tão escassa repercussão logrou em sua terra de origem. "A Krause estava reservada", na penetrante ponderação do Prof. MrgUel ReAle, "uma projeção inesperada no mundo hibérico. 0 fenômeno da ascendência krausiana, que ainda hoje causa estranheza a certos espíritos, foi quase que concomitante en Portugal e na Espanha." (A Doutrina de Kant no Brasil, in Revista da Facul-dade de Direito de São Paulo, Empresa Gráfica da Revista dos Tri-bunais Ltda., vol. 42, pág. 59). 
de la sociedad, assegurada por el poder coactivo del Esta.do." (25).

Para justificar a idéia de "condiçôes de vida da sociedade", alerta a atenção para as "condições de vida" em geral. Noção relativa, emergente das necessidades materiais (alimentação, vestuário, habitação) e das condições subjetivas (valores imateriais como a liberdade, a honra, o amor, etc.) que êle focaliza em uma página incisiva. (26).

Aquelas meras "condições", que com Krause começavam a derivar para o empirismo, sairam, assim, do plano

(25) Op. cit., no 180, pág. 213.

(26) Escreveu IhERing, naquele seu estilo inimitável que as próprias traduções não desmereceram, ao cuidar da noção das condições de vida da sociedade: "Para justificarlo es necessario que comprendamos la noción de las condiciones de vida.

Esta noción es relativa: se determina con arreglo a lo que constituye la vida. Si miramos esta desde el punto de vista de la existencia puramente fisica, dichas condiciones se limitan a las necesidades materiales de la vida: el comer, el beber, el vestido, la habitación. Pero aun bajo este aspecto, la noción sigue siendo relativa, porque se determina de diferente modo según las necesidades del individuo: éste exige más, aquél necesita otra cosa.

Pero la vida no se limita a existencia puramente fisica: el más humilde, el más desheredado, no se contenta con su sola conservación; no le basta con existir; aspira al bienestar. Cualquiera que sea el concepto que se forme de la existencia - porque uno empieza a vivir alli donde otro cree que la vida ha dicho su ultima palabra - la imagem ideal que se forja contiene para cada uno la medida del precio que fija a su vida real. Realizar este ideal constituye el fin de todos sus esfuerzos, el movil de su voluntad.

Llamo condiciones de vida a las condiciones subjetivas, que la rigem. Son condiciones de vida no sólo aquélas de las cuales depende la existencia fisica, sino también todos los bienes, los goces que, en el sentir del sujeto, son los unicos que dan valor a su existencia. El honor no es una condición de la vida fisica, y, sin embargo, para el hombre de honor, que valdria la existencia si éste estuviese perdido? Para guardarlo expone voluntario su 
lógico para, com IHenivg, se tornarem concretas por via da forma de "conjunto de condições de vida."

Sob o influxo dêsse enunciado, Pedro Lessa carreou para sua definição de direito a locução primordial, que nela se estampa, de "conjunto orgânico das condições de vida". Aditou-lhe o vocábulo orgânico que não altera a essencia.

Qualçuer incerteza sôbre essa adoção se dissiparia com a confissão do ilustre catedrático, feita em 1896, naquele estudo divulgado pela preciosa revista de nossa Faculdade de Direito. São palavras que ecoam: "E com algumas modificações a definição de Ihering, dir-se-á talvez. Sim, responderemos, é a definição de Inering, que por sua vez nada mais fêz do que reproduzir a definição de AHrens, para quem o direito consiste no conjunto orgânico das condições, dependentes da vontade, necessárias para a realização harmônica do destino humano.

A teoria científica do direito, repetimos, non venit solvere legem, sed adimplere eam.

Se acrescentamos às condições de vida garantidas pelo Estado as que o devem ser, è porque não há êrro mais grave do que supor com Ihering e com Puglia que o direito se distingue das demais normas éticas ùnicamente pela

existencia. La libertad, la nacionalidad, no son condiciones de la vida fisica; $y$ no hay un pueblo amante de la libertad que no haya preferido la muerte a la servidumbre. El que se mata por desprecio a la vida puede, sin embargo, reunir todas las condiciones exteriormente necesarias para la existencia. En una palabra: los bienes, los goces, de los cuales para vivir siente el hombre la necesidad, no solo tienen un carácter material; tienen además un valor immaterial, ideal; comprenden todo lo que es objeto de las luchas de la humanidad; el honor, el amor. la educación, la religión, las artes, la ciencia. La cuestión de las condiciones de vida, lo mismo del individuo que de la sociedad, es una cuestión de educación nacional e individual. "(Op. cit., no 181, págs. 213/214) 
sanção material, pelo emprêgo da coação física do Estado." (27).

Este contínuo fluxo e refluxo de idéias, "como ondas em um mar sem praias", teria impelido o pensamento de Ihering. Perfilhou-o, neste particular, Pedro Lessa, para integrar sua definição de direito.

8. Ter-se-á verificado, pela análise procedida, que a definição de direito dada por PEdno Lessa, como está afirmado de início, é u'a amálgama de idéias dos três grandes pensadores alemães aqui chamados nominalmente.

Era o direito, com Kant, o conjunto de condições de vida no plano estritamente lógico. Derivou para o plano empírico com Krause. E Ihering, que por último veio, atribuiu-lhe estôfo sociológico. Esta, a sinópse do enunciado. Resenha que, de certo modo, encontramos coincidentemente registrada pelo Prof. Miguel Reale. Dêle o reparo em seu denominado ensaio sôbre a doutrina de Kant: "As conhecidas definições de Gumercindo Bessa, Silvio Romero ou Pedro Lessa são meros arranjos pouco felizes de expressões de Ihering e de Krause, justapondose a idéia de condições existenciais da sociedade, empregada por um, com a nota de dependência da vontade humana apontada pelo segundo..." (28).

9. Conhecidos os fatôres que atuaram na definição do Direito, de autoria de Pedro Lessa, estamos habilitados a deduzir sôbre o valor atribuído à dogmática jurídica.

(27) Op. cit., vol. 4, pag. 31. Define, com efeito, AHrens, quando passa em análise a determinação metódica do principio de direito: "L'ensemble de conditions dependants de l'activité volontaire, - nécessaires pour la réalisation de tous les bens individuels, et sociaux qui forment la destination de l'homme et de la société." (Op. cit., pág. 160). Haveria em Ihering, no dizer de Pedro Lessa, a reprodução do mesmo sentido, levando-se mais longe as investigações.

(28) Op. cit., vol. 42 , pág. 92. 
Esses fatôres, dos quais não devemos desfitar os ol̉os, que traduzem as constantes dos filósofos que serviram de numes, afastam a dedução de que a dogmática jurídica não viram de numes, afastam a dedução de que a dogmática jurídica não se identificaria no campo da Ciência do Direito. Considerá-la simples arte, como passou a querer Pedro Lessa, é desconhecer ou negar a sua função aferidora; momento que dá à tarefa do jurista a peculiaridade científica.

Se o direito se ocupa com a ordenaçâo jurídica e a lei não é um simples instante expressional de sua experiência, não é crível que a dogmática jurídica, exposição sistemática das normas ou dogmas dêste ordenamento, deva ficar reduzida a um desempenho tão subalterno.

A estimativa de um conteúdo legal, em se enfrentando uma experiência concreta, reclama que se lhe reconheça um fenômeno de cultura, que não se lhe desinvista das características próprias.

10. Procurando mostrar a diferenciação entre ciência e arte, JoÃo Theodoro Xavier deduz: "Qualquer que seja o ramo de direito, pode não ser uma ciência, mas nunca será uma arte. São inconciliáveis as expressões arte jurídica." (29).

Sustenta êsse catedrático de filosofia, de conseguinte, a inexistência de arte do direito, já que o direito envolve a idéia de ciência e a arte a de "regras condicionais e utilitárias para benefício individual e social" (sic). Em sua compreensão será inaceitável a classificação da dogmática jurídica como arte porque "são inconciliáveis as expressões - arte jurídica." (sic).

Em sua preciosa contribuição, José Hygino Duarte Pereira, que tanto dignificou o Brasil na IIa. Conferência Pan-Americana realizada na cidade do México em 1901,

(29) Op. cit., § 9, págs. $6 / 7$. 
doutrina que "ciência do direito é sòmente aquela que tem por objeto a dogmática, o sistema, o organismo jurídico para estudá-lo nos seus fundamentos, nas suas regras e nos seus fins. Ela não se propõe a inquirir as causas e os efeitos do fenômeno jurídico, mas as normas que devem presidir às relações das pessoas. Como todo direito subjetivo supõe uma relação entre pessoas, é nessas relações que a nossa ciência encontra precisamente o seu objeto e os seus limites." (30).

Abrangendo a ciência do direito a teoria dogmática das relações, entre pessoas, com o desdobramento do ramo da jurisprudência, não haverá como se acolher, na opinião de José Hygivo Duarte Pereira, o caráter artístico para a dogmática jurídica.

11. No seu consagrado livro sôbre teoria do Estado, o Prof. Miguel Reale enfrenta o problema dando-lhe a soIução que serve de coroamento às investigações procedidas. Partiu êle do princípio de que a observação extremada obstará a ưma percepção exata para concluir que "a dogmática, portanto, deve ser entendida como parte da Ciência do Direito."

As premissas apresentadas, pela sua plausibilidade e para que seja acompanhada a evolução do raciocínio que merece prosperar, ecoam assim: "Parece-nos que há exageros de parte a parte, tanto entre os que identificam a Ciência Juridica com a Dogmática, quanto entre os outros que atribuem à Dogmática um papel secundário, de mera aplicação de elementos fornecidos pela Ciência Jurídica.

A concepção da Dogmática como uma arte ou a explanação de uma arte impede-nos de penetrar no verdadeiro objeto da Dogmática e é tão errônea como a teoria que levanta uma barreira entre a Ciência e a Técnica do Direito.

(30) in O Direito, Rio de Janeiro, Papelaria e Tipografia Mont' Alverne, vol. 63, pág. 167. 
Cumpre distinguir dois momentos na pesquisa do Direito, um em conexão ou continuidade lógica com o outro: o da elaboração científica dos princípios que em parte se concretizam no sistema das normas positivas; o da interpretação, construção e sistematização das normas do Direito positivo."

$\mathrm{E}$ após frisar a interpenetração dêstes dois momentos, “de tal sorte que não há interpretação de texto de lei, que não traga a ressonância dos fatos da vida concreta, nem apreciação de fatos que não sofra a refração do sistema legal vigente", lança o atual titular da cadeira de Filosofia do Direito em nossa Faculdade de Direito, a segura conclusão: "A Dogmática, portanto, deve ser entendida como parte da Ciência do Direito, correspondente ao momento culminante da jurisprudência, àquele no qual os resultados da pesquisa - as normas e os princípios científicos tornam a tomar contacto com os fatos, passam, por assim dizer, pela prova decisiva da aferição de seu valor real. Em verdade não é menos nem mais científico êste momento, porventura mais caracteristicamente juridico, no qual há criação, há participação criadora do interprete (doutrinador, administrador, juiz, etc.) que refaz o caminho percorrido, renova o processo por que passaram os que editaram a lei, a fim de aplicar, não a norma ao fato particular como se veste uma roupa standard em um manequim, mas para iluminar o fato com a luz dos valores que se concretizam na regra de Direito." (31).

Depois de uma década vencida no tempo, voltou o Prof. Miguel Reale ao tema: confiante nas conquistas da cultura e com o mesmo senso agudo de pesquisa, deu a última lição aos bacharelandos de 1951. Foi na sua oração de paraninfo, abundante de ensinamentos. Dela recolhemos a passagem com que finalizaremos a fundamentação dêste despretencioso trabalho de investigação: "A Ciência do Direito não se confunde, porém, com Dogmática Jurídica,

(31) Op. cit., no 9 , págs. 13/15. 
que é apenas um momento, embora necessário e conclusivo, do trabalho científico do jurista. Se a Dogmática é a interpretação da realidade ou da experiência juridica de um povo em dada época, tal como decorre dos preceitos vigentes; se ela se desdobra no fino lavor interpretativo das normas. na construção dos institutos como unidades moleculares da doutrina e se eleva à organicidade dos sistemas, não há como desmerecer seu papel, que por si só poderia justificar a grandeza de nosso mister de advogados e juizes. Mas não é dito que a Cièncía do Direito se esgote na Dogmática ou que com ela se confunda. Não faltaram nem faltam ainda hoje, juristas apegados a essa identificação, mas um exame das raízes do problema parece demonstrar que não é menos Ciência do Direito aquêle complexo de exigências e categorias lógicas e axiológicas que condiciona o aparecimento mesmo da Lei, destinada a ser recebida e aceita pela Dogmática como um dado, um pressuposto de suas construções normativas.

Ciomo negar o momento de juridicidade da legislação $e$, por conseguinte, ccmo ignorar a condicionalidade científica da obra do legislador? Aquela penada que aparentemente deita abaixo uma biblioteca já está carregada de fôrça normativa e, não raro, representa o resultado de novas exigências do justo operando na consciência de um povo; ela pressupõe outras bibliotecas. "(32).

12. Revivendo idéias, sob o lume da boa vontade, vemos, afinal, flutuar o tema proposto. Não terá, por certo, as proporções de verdade apurada, e tão pouco vida própria, mas, servirá para traduzir a nossa convicção em tôrno do assunto: - a dogmática juridica não pode ser subestimada e reduzida a simples arte representando, antes, como integrante da Ciência do Direito, o momento pinacular de juridicidade normativa.

(32) De Dignitate Jurisprudentiae, S. Paulo, 1952, Emprêsa Gráfica da Revista dos Tribunais, pág. 31. 